\title{
Syringe exchange not associated with social network formation: results from Baltimore
}

\section{Benjamin Junge $^{a}$, Thomas Valente ${ }^{b}$, Carl Latkinc, Elise Riley ${ }^{a}$ and David Vlahov ${ }^{a}$}

\begin{abstract}
Objective: To examine possible formation of new social contacts at the Baltimore Syringe Exchange Program (SEP).

Design: Systematic sub-sample of new SEP participants recruited into evaluation cohort for biannual interviews. This analysis used 6-month interview data.

Methods: Participants were interviewed for behavioral and network characteristics, and number of new social contacts formed at the SEP. Variables were cross-tabulated using $\chi^{2}$ statistics.

Results: Of 413 participants interviewed, 32 (8\%) said they had made at least one social contact at the SEP. These 32 individuals were more likely to have engaged in commercial sex (16 versus $3 \%, P=0.005)$ and, among active injectors, were more likely to have used syringes obtained from other drug users (22 versus $8 \%, P=0.026$ ).

Conclusions: Findings argue against the formation of new social networks (and therefore new disease transmission networks) in the context of syringe exchange participation.

(c) 2000 Lippincott Williams \& Wilkins
\end{abstract}

AIDS 2000, 14:423-426

Keywords: AIDS, needle and syringe exchange, prevention programs

\section{Introduction}

Recently, it has been suggested that syringe exchange programs (SEPs), which provide injection drug users (IDUs) with sterile replacements for their used syringes, might encourage the formation of new social networks [1]. As SEPs are commonly patronized by individuals who may not be previously acquainted with each other, it is possible that exchangers could forge new social contacts at some point during a visit to the exchange (e.g. while waiting in line to exchange). If true, this network formation might confer benefits on SEP participants (e.g. transfer of information on HIV prevention and local social service resources). Conversely, formation of new networks or crossover among networks (also known as 'mixing') could result in increased disease transmission [2]. In other words, network formation might be associated with negative outcomes (i.e. the introduction of HIV or other infections into uninfected networks) if 'low risk' injectors are being linked with 'high risk' injectors. Presumably, individuals at particularly high risk of transmitting infection would be seropositive syringe lenders; similarly, seronegative exchangers who borrow syringes would be at a relatively high risk of acquiring infection as a consequence of a newly formed social contact. To date, however, reports on the salience of the social network formation hypothesis in the context of actual SEPs are sparse $[3,4]$. Here, we report on a study carried out in Baltimore, Maryland, among participants in a largescale, van-based SEP.

From the Departments of a Epidemiology, ${ }^{\mathrm{b}}$ Department of Population and Family Health Sciences, and ${ }^{\mathrm{c}}$ Health Policy and Management; The Johns Hopkins University School of Hygiene and Public Health, Baltimore, Maryland, USA.

Sponsorship: Supported by grant DA09237 from the National Institute on Drug Abuse. Grant number DA10172

Correspondence to Benjamin Junge, MHS, Johns Hopkins School of Public Health, 627 N. Washington St., Baltimore, MD 21205, USA.

Tel: +1 4106143632 ; fax +1 4106149910

Received: 12 January 1999; revised: 8 October 1999; accepted: 23 November 1999. 


\section{Materials and methods}

To determine the extent of formation of new social contacts at sites of the Baltimore SEP and to examine possible associations between network formation and demographic and behavioral variables, we recruited a systematic sample of new exchangers into an evaluation study cohort for interviewing and voluntary HIVtesting at 6-month intervals. Specifically, every seventh new enrollee was invited to participate in an evaluation study. As Maryland state law mandates that SEP enrollment be anonymous, it was not possible to obtain information that could be used to contact study participants to remind them of future interviews. To maximize retention, however, participants were provided with follow-up appointment cards and were reminded on subsequent visits to the SEP van to exchange syringes. The present analysis uses data from interviews administered 6 months after SEP enrollment. Individuals were scheduled to return for follow-up visits regardless of whether they continued to inject drugs. (We thus anticipated that some proportion of the sample used for this analysis would be noninjectors.) All data collection for this study took place between February 1995 and February 1997. Interview topics included demographics, drug and syringe use, sex practices, personal network characteristics and number of social contacts formed at the SEP since enrollment. Personal network characteristics included network size (number of close friends), and density (the extent to which the respondent's friends know each other); formation of new social contacts was gauged by responses to the question: 'in the past 6 months, how many people did you meet at the needle exchange who you have spent time with at least once away from the needle exchange?' Variables were cross-tabulated with recent formation of contacts at the SEP $(\mathrm{Y} / \mathrm{N})$ using $\chi^{2}$ statistics.

\section{Results}

Of 796 new subjects recruited into the evaluation study, $413(51.8 \%)$ returned for a 6-month interview. Of the 413 individuals, 277 (67.1\%) were men. With respect to race/ethnicity, $378(91.5 \%)$ were AfricanAmerican, four $(1.0 \%)$ were Caucasian, one $(0.2 \%)$ was an Asian/Pacific Islander, and 29 (7.3\%) described their race/ethnicity as 'other'. A total of 283 (68.5\%) were single, and 373 (90.3\%) were unemployed. Individuals used in this analysis were slightly older than those lost to follow-up ('dropouts') (age 39.1 versus 37.1 years, $P=0.020)$, but statistically similar with respect to all other demographic variables measured (data not shown).

Of the 413 individuals in the sample, 128 (29.8\%) were
HIV seropositive and 351 (85.0\%) were active injectors. Among active injectors, 295 (84.0\%) reported injection at least daily during the previous 6 months, with a mean daily injection frequency of 4.4 (median $=3.3$ ). The behavior of passing along one's own used syringes to another injector was reported by 77 $(21.9 \%)$ of this sample's active injectors; use of other injectors' used syringes was reported by 32 individuals $(9.1 \%)$.

Within the sample of 413 individuals, 32 (7.7\%) reported having met at least one person at the SEP van since enrollment. For those who met someone, the mean number of contacts made was 3.3 (median $=2$ ). Table 1 compares individuals who met at least one person with those who did not meet someone, with respect to demographics, drug and syringe use, sex practices, and personal network characteristics. People who met at least one person were more likely to have traded sex for drugs or money during the previous 2 weeks $(15.6$ versus $2.9 \%, P=0.005)$. Among active injectors, people who met someone were less likely to have injected at least daily (70.4 versus $85.2 \%, P=0.047$ ) and more likely to have reported use of other injectors' used syringes $(22.2$ versus $8.0 \%, P=0.026$ ). In a logistic regression model with these three variables entered as covariates, only the variables use of others syringes and commercial sex were independently associated with at least one recently formed social contact at an SEP site. On all other variables, there were no statistically significant differences between those who met someone and those who did not. Among seropositive individuals who met someone $(n=10)$, two $(20 \%)$ reported recent syringe lending; of seronegatives who met somebody $(\mathrm{n}=17)$, four $(23.5 \%)$ reported recent syringe borrowing.

\section{Discussion}

The major finding from this study is that 6 months after enrollment into the Baltimore SEP, the majority of this sample $(92.3 \%)$ reported no new social contacts made at exchange sites. This finding is consistent with recent reports from Montreal and Vancouver, Canada $[3,4]$. Moreover, among individuals who met someone, only one-fifth of seropositives reported lending syringes recently and about a quarter of seronegatives reported syringe borrowing.

Among the 32 individuals who did meet somebody at the SEP van, we noted a discrepancy between the mean and median number of contacts made (3.3 versus 2 , respectively), which suggests that possibility that one or more outliers may be skewing the group average. Looking more closely at the data, this turns out to be 
Table 1. Demographic, behavioral and network profile of sample, 6 months following syringe exchange program (SEP) enrollment, crosstabulated by recent formation of social contacts at SEP site $(n=413)^{\text {a }}$.

\begin{tabular}{|c|c|c|c|c|c|}
\hline \multirow[b]{3}{*}{ Characteristic } & \multicolumn{4}{|c|}{ Met someone at SEP site, past 6 months? } & \multirow[b]{3}{*}{$P$-value } \\
\hline & \multicolumn{2}{|c|}{ Yes $(n=32)$} & \multicolumn{2}{|c|}{ No $(\mathrm{n}=381)$} & \\
\hline & $\mathrm{n}$ & $\%$ & $\mathrm{n}$ & $\%$ & \\
\hline Age (years) [mean (median)] & 39.7 & $(40.5)$ & 39.1 & $(39.1)$ & NS \\
\hline \multicolumn{6}{|l|}{ Sex } \\
\hline male & 21 & 65.6 & 257 & 67.6 & NS \\
\hline female & 11 & 34.4 & 123 & 32.4 & \\
\hline \multicolumn{6}{|l|}{ Race/ethnicity } \\
\hline African-American & 27 & 84.4 & 351 & 92.4 & NS \\
\hline Caucasian & 1 & 3.1 & 3 & 0.8 & \\
\hline Asian & 0 & 0.0 & 1 & 0.3 & \\
\hline Other & 4 & 12.5 & 25 & 6.6 & \\
\hline \multicolumn{6}{|l|}{ Marital status } \\
\hline single/never married & 3 & 9.4 & 28 & 7.5 & NS \\
\hline separated/divorced & 10 & 31.3 & 81 & 21.7 & \\
\hline married & 19 & 59.4 & 264 & 70.6 & \\
\hline \multicolumn{6}{|l|}{ Employment status } \\
\hline employed & 2 & 6.3 & 26 & 7.0 & NS \\
\hline unemployed & 30 & 93.8 & 343 & 91.7 & \\
\hline \multicolumn{6}{|l|}{ HIV status } \\
\hline positive & 10 & 33.3 & 113 & 31.2 & NS \\
\hline negative & 20 & 66.7 & 249 & 68.8 & \\
\hline \multicolumn{6}{|l|}{ Injection status } \\
\hline active & 27 & 84.4 & 324 & 85.0 & NS \\
\hline not active & 5 & 15.6 & 57 & 15.0 & \\
\hline \multicolumn{6}{|l|}{ At least daily injection } \\
\hline yes & 19 & 70.4 & 276 & 85.2 & $<0.05$ \\
\hline no & 8 & 29.6 & 48 & 14.8 & \\
\hline Injection frequency (times per day) [mean (median)] & 4.5 & $(3.1)$ & 4.4 & (3.3) & NS \\
\hline \multicolumn{6}{|l|}{ Syringe borrowing $b_{, c}$} \\
\hline yes & 6 & 22.2 & 26 & 8.0 & $<0.05$ \\
\hline no & 21 & 77.8 & 298 & 92.0 & \\
\hline \multicolumn{6}{|l|}{ Syringe lending ${ }^{b, d}$} \\
\hline yes & 8 & 29.6 & 69 & 21.3 & NS \\
\hline no & 19 & 70.4 & 255 & 78.7 & \\
\hline \multicolumn{6}{|l|}{ Sexually active during past 2 weeks } \\
\hline yes & 13 & 40.6 & 208 & 54.6 & NS \\
\hline no & 19 & 59.4 & 172 & 45.1 & \\
\hline \multicolumn{6}{|l|}{ Sex with IDU during past 2 weeks } \\
\hline yes & 10 & 31.3 & 78 & 20.5 & NS \\
\hline no & 22 & 68.8 & 303 & 79.5 & \\
\hline \multicolumn{6}{|l|}{ Sex in exchange for drugs or money during past 2 weeks } \\
\hline yes & 5 & 15.6 & 11 & 2.9 & $<0.01$ \\
\hline no & 27 & 84.4 & 370 & 97.1 & \\
\hline \multicolumn{6}{|l|}{ Sex with someone who is HIV seropositive } \\
\hline yes & 2 & 6.3 & 6 & 1.6 & NS \\
\hline no & 30 & 93.8 & 375 & 98.4 & \\
\hline Personal network size [mean (median)] & 3.3 & (3) & 2.9 & (3) & NS \\
\hline Personal network density [mean (median)] & 0.84 & $(1.00)$ & 0.87 & $(1.00)$ & NS \\
\hline
\end{tabular}

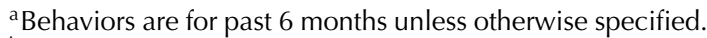

${ }^{b}$ Limited to sub-sample of active injectors $(n=351)$.

${ }^{\mathrm{c}}$ Defined as using another person's used syringes.

'Defined as passing on one's own used syringes to another injector.

eWhere expected values in $2 \times 2$ tables were less than 5, Fisher's exact test was used to generate $P$-values. Pearson's $\chi^{2}$ was used for all other dichotomous variables. For continuous variables, $P$-values were generated from one-way analysis of variance.

IDU, injecting drug user.

the case: one individual, reporting 30 recent contacts (more than three-and-a-half times as much as for the individual who reported the next highest quantity), is clearly skewing the mean. Additional research would do well to follow up with an ethnographic method- ology to better understand the motivations of these individuals.

This study is limited by attrition from the original sample. In a separate analysis geared to examine 
differences between returnees and dropouts more closely (data not shown), we compared the two groups with respect to baseline personal network size and density (using these as proxies of a baseline measures of sociality) but found no significant differences. We also considered the possibility that individuals who were unemployed or more frequent injectors would be more likely to come back (i.e. greater need for cash-inflow in the form of remuneration for 6-month interview), but subsequently found no significant differences in these variables. Statistical similarity between dropouts and returnees on virtually all variables except age thus strengthens confidence in inferences. Future research is needed to better understand the individuals with whom some exchangers forge contacts, as well as a possible association between formation of new social contacts and adverse health outcomes. To explore a potentially positive benefit of new contacts formed at SEP sites (e.g. transfer of health education), it is important to study the nature of newly forged relationships and the topical discussions that they enable.

Evaluation of HIV prevention programs such as SEPs is important not only to establish effectiveness, as has been carried out in New York [5] and Tacoma [6], but also to identify possible unintended consequences. The original hypothetical concern that SEPs might congregate previously unlinked IDUs at exchange sites, encouraging the formation of new networks and thereby creating potential disease transmission networks, is unsupported by our data. Taken together, our findings argue against major formations of new social networks, and therefore new disease transmission networks, in the context of syringe exchange participation.

\section{Acknowledgements}

The authors gratefully acknowledge the following individuals: Michele Brown, Lamont Coger, Eric Peck, Gary Alsup, Edward Washington, Antonio Norman, Surrendor McKnight and Warren Beads for daily operations on the SEP van; Martha Decker, Jason Langley and John Vertefeuille for data collection. We are also indebted to the individuals who participated in this study.

\section{References}

1. Bruneau J, Lamothe $F$, Franco $E$, et al. High rates of HIV infection among injection drug users participating in needle exchange programs in Montreal: results of a cohort study. Am J Epidemiol 1997, 146:994-1002.

2. Morris $M$, Kretzschmar $M$. Concurrent partnerships and transmission dynamics in networks. Social Networks 1995, 17: 299-318.

3. Lamothe F, Bruneau J, Franco E, Lachance N, Vincelette J. New sharing partners encounter places among needle exchange attenders. 12th World AIDS Conference, Geneva, June 1998 [abstract 23187].

4. Schechter $M$, Strathdee $S A$, Currie DM, et al. Harm reduction, not harm production: needle exchange does not promote HIV transmission among injection drug users in Vancouver, Canada. 12th World AIDS Conference, Geneva, June 1998 [abstract 33379].

5. Des Jarlais DC, Marmor M, Paone D, et al. HIV incidence among injecting drug users in New York City syringe-exchange programmes. Lancet 1996, 348:987-991.

6. Hagan H, Des Jarlais DC, Friedman SR, Purchase D, Alter MJ. Reduced risk of hepatitis $B$ and hepatitis $C$ among injecting drug users participating in the Tacoma syringe exchange program. Am J Public Health 1995, 85:1531-1537. 